\title{
La estrategia europea de RSE 2011-2014: Análisis del punto de partida para un plan de acción de RSE en España
}

European CSR Strategy 2011-2014: Analysis of the starting point for a CSR action plan in Spain

Germán Granda

Forética

ggranda@foretica.es
Granda, G. (2012). La estrategia europea de RSE 2011-2014: Análisis del punto de partida para un plan de acción de RSE en España. Revista Internacional de Investigación en Comunicación aDResearch ESIC. No 6 Vol 6. Segundo semestre, julio-diciembre 2012. Págs. 52 a 65 DOI: 10.7263/ADR.RSC.006.03 
JEL Classification:

M14

Palabras clave:

Estrategia, responsabilidad,

social,

empresas,

Europa,

España

El 25 de Octubre de 2011 la Comisión Europea publicó la Comunicación de la Comisión al Parlamento Europeo, al Consejo, al Comité Económico y Social Europeo y al Comité de Regiones que lleva como título "Estrategia renovada de la UE para 2011-2014 sobre la responsabilidad social de las empresas". En dicha estrategia se establece, además de una nueva definición de responsabilidad social de las empresas (RSE), trece compromisos de la comisión europea, una propuesta legislativa para el reporting de RSE y cinco invitaciones a gobiernos y otros grupos de interés para que se incorporen a la estrategia. En el periodo 2008-2011 la Ley de economía sostenible (LES) y la creación del Consejo Estatal de RSE (CERSE), han sido las iniciativas de calado para que España incorporase un discurso y acciones en RSE. La nueva estrategia europea brinda a España la posibilidad de establecer su primera estrategia nacional de RSE en coordinación con la europea. Es el momento de revisar lo que se ha hecho y constatar si existen aspectos en los que España pueda todavía ejercer cierto liderazgo así como constatar que la RSE en su concepción de aunar eficiencia, innovación y competitividad puede ser, como constata la estrategia europea, un argumento de gran potencial para contrarrestar la crisis.

\section{ABSTRACT}

\section{Clasificación JEL:}

M14

Key words:

strategy, accountability, social, business, Europe, Spain
On October 25th, 2011 the European Commission published the Communication from the Commission to the European Parliament, the Council, the European Economic and Social Committee and the Committee of Regions entitled "Renewed EU strategy on corporate social responsibility for 2011-2014". In addition to a new definition of corporate social responsibility (CSR), this strategy established thirteen commitments by the European Commission, a legislative proposal for the reporting of CSR and five invitations to governments and other stakeholders to become involved in the strategy. In the period 2008-2011, the Sustainable Economy Law (LES in Spanish) and the creation of the CSR State Board (CERSE in Spanish) have represented significant Spanish efforts to develop policies and actions related to CSR. The new European strategy offers Spain a clear opportunity to establish its first national CSR strategy in coordination with European efforts. The time has come to review previous policies and decide if there are areas in which Spain can still attain some leadership. Furthermore, through its conception of combining efficiency, innovation and competitiveness, CSR may become a significant factor in overcoming the current economic crisis, as noted by the European strategy. 


\section{Antecedentes}

La cumbre de Lisboa del año 2000 hizo por primera vez un llamamiento por parte de los jefes de estado y de gobierno para que las empresas asumieran un compromiso con la responsabilidad social. En el año 2001 la Comisión Europea publicó el Libro Verde de la responsabilidad social empresarial donde definió el concepto de la responsabilidad social de las empresas (RSE) como «la integración voluntaria, por parte de las empresas, de las preocupaciones sociales y medioambientales en sus operaciones comerciales y sus relaciones con sus interlocutores».

Desde entonces la Comisión Europea ha creado el Foro Multilateral Europeo sobre la RSE y ha publicado tres comunicaciones referentes a la RSE. Una inicial en el año 2002, la comunicación del 2006 donde impulsó la Alianza Europea para la RSE y la última de 25 de octubre de 2011. Aunque en los últimos años se ha podido constatar un incremento del interés, las políticas de gobiernos europeos y las prácticas en empresas en materia de RSE

\begin{tabular}{|c|c|c|}
\hline Iniciativa & $\begin{array}{l}\text { Empresas } \\
2006\end{array}$ & $\begin{array}{l}\text { Empresas } \\
2011\end{array}$ \\
\hline $\begin{array}{l}\text { Pacto Mundial de Naciones } \\
\text { Unidas }\end{array}$ & 600 & 1900 \\
\hline $\begin{array}{l}\text { Sistema de Gestión y Auditoría } \\
\text { Medioambientales (EMAS) }\end{array}$ & 3300 & 4600 \\
\hline $\begin{array}{l}\text { Acuerdos transnacionales con } \\
\text { organizaciones de trabajadores } \\
\text { sobre normas laborales }\end{array}$ & 79 & 140 \\
\hline BSCI Initiative & 69 & 700 \\
\hline Informes GRI & 270 & 850 \\
\hline
\end{tabular}

Fuente: Comunicación Comisión Europea RSE 2011 (mayor número de informes de RSE, por ejemplo tal como refleja la tabla 1) es necesario un esfuerzo mayor en este ámbito ya que se mantienen algunos retos fundamentales. Por ejemplo, todavía muchas empresas no tienen una política de RSE o no la han integrado en su estrategia y operaciones. Además, la Comisión Europea constata que el cumplimiento de los derechos humanos y estándares laborales mínimos es todavía una preocupación.

\section{2. ¿Por qué es necesaria una nueva estrategia de RSE?}

La necesidad de una nueva estrategia la podemos concretar en 4 razones fundamentales.

En primer lugar, resultaba necesario que específicamente se articulara la aportación de la RSE a la estrategia global europea, denomina da la estrategia Europa 2020 para un crecimiento inteligente, sostenible e inclusivo. Esta demanda ha sido trasladada tanto por el Consejo europeo como por el Parlamento Europeo. Además, tanto en la Comunicación europea sobre una política industrial de 2010 como en el Acta del Mercado Único ya afirmó la comisión que presentaría una nueva iniciativa sobre la RSE.

En segundo lugar, era necesario adaptar el discurso de la RSE a las nuevas circunstancias. Por ejemplo, como parte de la estrategia de salida a la crisis económica y social. El Informe de competitividad 2008 de la comisión europea ya mostraba las ventajas de incorporar políticas de RSE en las empresas (beneficios en cuanto a gestión de riesgos, ahorro de costes, acceso al capital, relaciones con los clientes, gestión de los recursos humanos y capacidad de innovación), muy necesarios en la situación actual y con el potencial de impulsar el desarrollo de nuevos mercados y nuevas oportunidades de 
crecimiento. No se debe tampoco minusvalorar el potencial de las políticas bien orientadas de RSE para reforzar la confianza de empleados, consumidores y ciudadanos que perciban modelos empresariales más responsables y sostenibles.

En tercer lugar, es necesario en estos momentos también reafirmar el liderazgo en materia de RSE de la Unión europea y aumentar su influencia en un entorno donde se han generado en los últimos años nuevas herramientas globales de RSE (la ISO 26,000, las líneas directrices de la OCDE para multinacionales, la declaración tripartita de principios sobre las empresas multinacionales y la política social de la OIT y, por último, el marco de Naciones Unidas de negocios y derechos humanos, entre otros).

Por último, en los últimos años han surgido en Europa diferentes estrategias y planes de acción nacionales en materia de RSE entre los que destacan el plan de acción del gobierno de la república federal de Alemania o el plan del gobierno danés. Los gobiernos de España, Reino Unido, Suecia o Francia, por citar sólo algunos, han incorporado también iniciativas al acervo de prácticas de RSE. La nueva estrategia resulta relevante en este momento para guiar y coordinar las políticas de RSE de los gobiernos nacionales, evitando así aproximaciones divergentes $\mathrm{y}$, por tanto, contraproducentes.

\section{Una nueva definición de RSE}

Quizá uno de los elementos más novedosos que presenta la nueva estrategia europea es la nueva definición de RSE. La nueva definición establece que la RSE es «la responsabilidad de las empresas por su impacto en la sociedad». Dada la limitación de la definición, fundamen- tada en la necesidad de sencillez, la comunicación perfila que "el respeto de la legislación aplicable y de los convenios colectivos entre los interlocutores sociales es un requisito previo al cumplimiento de dicha responsabilidad". Es decir, reincide en que la RSE supone ir más allá del cumplimiento de la legislación y además refuerza el papel del diálogo al destacar que "para asumir plenamente su responsabilidad social, las empresas deben aplicar, en estrecha colaboración con las partes interesadas, un proceso destinado a integrar las preocupaciones sociales, medioambientales y éticas, el respeto de los derechos humanos y las preocupaciones de los consumidores en sus operaciones empresariales y su estrategia básica". Por último, se reafirma en una RSE que más allá de centrarse en la gestión de riesgos, donde las empresas deben identificar, prevenir y atenuar sus posibles consecuencias adversas, se abre a las posibilidades de "maximizar la creación de valor compartido para sus propietarios/accionistas y para las demás partes interesadas y la sociedad en sentido amplio".

\section{La agenda para la acción de la Comisión Europea 2011 - 2014}

En el apartado de compromisos de la Comisión Europea es donde la estrategia cobra más fuerza. Además establece un serie de sugerencias para las empresas, los Estados miembros y otros grupos de partes interesadas, destacando en todo momento su sensibilidad hacia las características particulares de las PYME evitando la creación de "cargas administrativas innecesarias". Sin ánimo de ser exhaustivo se incluyen en la tabla 2 las siguientes 8 líneas estratégicas que establece la Comisión Europea, con los 13 compromisos concretos establecidos: 


\section{Tabla 2 - Líneas estratégicas y compromisos de la Comisión europea}

\begin{tabular}{|c|c|c|c|}
\hline Líneas estratégicas (8) & Compromisos comisión europea $(13+1)$ & Fecha & Destinatarios \\
\hline $\begin{array}{l}\text { Mejora de la visibilidad de la RSE } \\
\text { y difusión de buenas prácticas }\end{array}$ & $\begin{array}{l}\text { 1. Crear plataformas multilaterales sobre RSE en diver- } \\
\text { sos sectores industriales a fin de alcanzar compro- } \\
\text { misos públicos sobre cuestiones de RSE de interés } \\
\text { para cada sector y hacer un seguimiento conjunto } \\
\text { de los avances; } \\
\text { 2. Premio Europeo para asociaciones sobre RSE entre } \\
\text { empresas y otras partes interesadas. }\end{array}$ & 2012 & $\begin{array}{l}\text { Empresas de } \\
\text { sectores industriales } \\
\text { Empresas junto a } \\
\text { grupos de interés }\end{array}$ \\
\hline $\begin{array}{l}\text { Mejora y seguimiento de } \\
\text { la confianza en las empresas }\end{array}$ & $\begin{array}{l}\text { 3. tratar el problema del marketing engañoso en rel- } \\
\text { ación con las consecuencias medioambientales de } \\
\text { los productos en el contexto de la Directiva de prác- } \\
\text { ticas comerciales desleales y estudiar la adopción de } \\
\text { medidas especíicas; } \\
\text { 4. debate abierto con ciudadanos, empresas y partes } \\
\text { interesadas sobre el papel de las empresas en el } \\
\text { siglo XXI, y realizar encuestas periódicas sobre la } \\
\text { confianza de los ciudadanos en las empresas y las } \\
\text { actitudes hacia la RSE. }\end{array}$ & Sin fecha & $\begin{array}{l}\text { Empresas } \\
\text { Ciudadanos, empre- } \\
\text { sas y partes intere- } \\
\text { sadas }\end{array}$ \\
\hline $\begin{array}{l}\text { Mejora de los procesos de } \\
\text { autorregulación y corregulación }\end{array}$ & $\begin{array}{l}\text { 5. Elaboración de un código de buenas prácticas sobre } \\
\text { autorregulación y corregulación que debe mejorar } \\
\text { la eficacia del proceso de RSE. }\end{array}$ & 2012 & Empresas \\
\hline $\begin{array}{l}\text { Mejora de la recompensa } \\
\text { que supone la RSE en el mer- } \\
\text { cado }\end{array}$ & $\begin{array}{l}\text { 6. Facilitar una mejor integración de las consideracio- } \\
\text { nes sociales y medioambientales en la contratación } \\
\text { pública, sin añadir cargas administrativas ni cues- } \\
\text { tionar el principio de la adjudicación de los contra- } \\
\text { tos a las propuestas más rentables. } \\
\text { 7. estudiar el requisito de que todos los fondos de } \\
\text { inversión e instituciones financieras informen a sus } \\
\text { clientes sobre cualquier criterio de inversión ético } \\
\text { o responsable que apliquen o cualquier norma o } \\
\text { código al que se adhieran. }\end{array}$ & Sin Fecha & $\begin{array}{l}\text { Administración } \\
\text { pública y empresas } \\
\text { Fondos de inversión } \\
\text { e instituciones } \\
\text { financieras }\end{array}$ \\
\hline $\begin{array}{l}\text { Mayor integración de la RSE en } \\
\text { la educación, la formación y la } \\
\text { investigación }\end{array}$ & $\begin{array}{l}\text { 8. ofrecer más apoyo financiero a proyectos de edu- } \\
\text { cación y formación sobre RSE y sensibilizar a los } \\
\text { profesionales de la educación y las empresas sobre } \\
\text { la importancia de la cooperación. }\end{array}$ & 2012 & $\begin{array}{l}\text { Academia, investiga- } \\
\text { dores y empresas }\end{array}$ \\
\hline $\begin{array}{l}\text { Insistencia en la importancia de } \\
\text { las políticas nacionales y subna- } \\
\text { cionales sobre RSE }\end{array}$ & $\begin{array}{l}\text { 9. crear con los Estados miembros, un mecanismo } \\
\text { de revisión por pares de las políticas nacionales en } \\
\text { materia de RSE. }\end{array}$ & 2012 & Gobiernos nacionales \\
\hline $\begin{array}{l}\text { Mejora de la armonización de } \\
\text { los enfoques europeo y mundial } \\
\text { sobre RSE }\end{array}$ & $\begin{array}{l}\text { 10. seguimiento del compromiso adquirido por las } \\
\text { empresas europeas con más de } 1000 \text { trabajadores } \\
\text { de tomar en consideración los principios y directri- } \\
\text { ces sobre RSE y la norma de orientación ISO } 26000 \\
\text { sobre responsabilidad social en sus operaciones. } \\
\text { 11. trabajar con empresas y las partes interesadas en } \\
\text { elaborar orientaciones sobre derechos humanos } \\
\text { para sectores industriales pertinentes, así como } \\
\text { para pymes, sobre la base de los Principios Recto- } \\
\text { res de la ONU; }\end{array}$ & Sin fecha & $\begin{array}{l}\text { Empresas y grupos } \\
\text { de interés }\end{array}$ \\
\hline
\end{tabular}




\section{Mejora de la armonización de los enfoques europeo y mundial sobre RS}

\section{Mejora de la divulgación de} información de carácter social y medioambiental por parte de las empresas
12. publicar informe sobre las prioridades de la UE en la aplicación de los Principios Rectores de la ONU y emitir informes de situación periódicos.

13. promover el comportamiento responsable de las empresas en terceros países.

$13+1$. Nueva propuesta legislativa sobre reporting RSE

\begin{tabular}{l|l}
\hline 2012 & Empresas \\
\hline Sin fecha & Empresas \\
\hline & \\
\hline 2012 & Empresas
\end{tabular}

2012

Empresas
Probablemente, la medida que se puede considerar "estrella" dentro de este paquete de acciones es la propuesta legislativa sobre la transparencia de la información social y medioambiental para las empresas en todos los sectores. Esta medida, ya anunciada en el acta del mercado único está prevista que se adopte en el primer semestre de 2012 durante la presidencia de Dinamarca.
Junto a los $13(+1)$ compromisos, la Comisión Europea en las diferentes líneas estratégicas incorpora 5 invitaciones adicionales a que diversos grupos de interés actúen, tal como muestra la tabla 3:

Probablemente entre las invitaciones de la Comisión Europea la más relevante sea la de instar a los gobiernos nacionales a desarrollar sus pro-

\section{Tabla 3 • Invitación a la acción a grupos de interés}

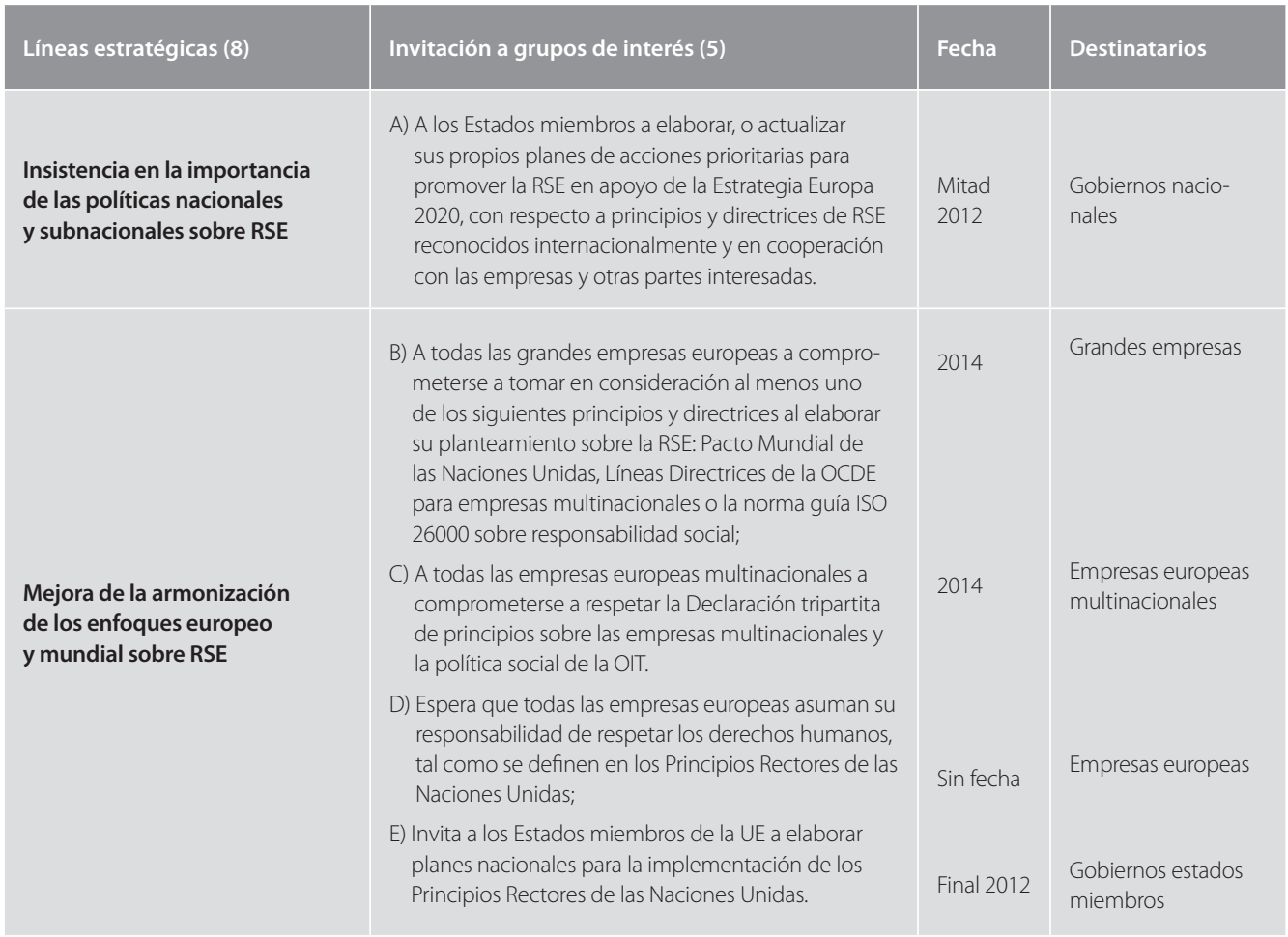


pios planes de acción en RSE para el período 2011 -2014. La existencia de estos planes nacionales y su estrategia en cuanto a objetivos alineados con la estrategia Europa 2020 como promoción de herramientas a utilizar por empresas y organizaciones será vital en los próximos años para el éxito de la RSE.

Además de la presente comunicación, existen otras iniciativas dentro de la estrategia Europa 2020 vinculadas a la promoción de la RSE. Aunque no es objeto del presente artículo analizarlas en su totalidad, se considera relevante mencionar las más relevantes que pudieran ser las siguientes:

- Política Industrial Integrada en la era de la globalización COM (2010) 614

- La Plataforma Europea en contra de la Pobreza y exclusión social COM (2010) 758

- La Agenda para Nuevas habilidades y trabajo COM (2010) 682

- Youth on the Move COM (2010) 477

- El Acto del Mercado Único (Single Market Act) COM (2011) 206

Adicionalmente, la Unión de Innovación COM (2010) 546 tiene como objetivo aumentar la capacidad de las empresas para responder a retos sociales a través de la innovación y la contribución de las empresas es esencial para cumplir con los objetivos de la iniciativa estratégica «Una Europa Eficiente en Recursos»

\section{La agenda pública en España 2008-2011}

En España la agenda pública en RSE durante el período 2008-2011 ha corrido en paralelo al desarrollo europeo fomentando los debates sobre el concepto y mejores estrategias de RSE, identificando los principales actores, hasta la concre- ción de algunos aspectos fundamentalmente a través de la Ley de Economía Sostenible.

El primer hito destacado en este período fue la creación en enero de 2009 del Consejo Estatal de Responsabilidad Social de las Empresas (CERSE), como órgano consultivo del Gobierno para impulsar y fomentar las políticas de RSE. El Consejo, compuesto por 56 miembros y presidido por el Ministro de Trabajo e Inmigración cuenta con la participación de los siguientes agentes sociales: sindicatos y organizaciones empresariales, las Administraciones públicas (central, autonómica y local) y otras organizaciones e instituciones de reconocida representatividad en al ámbito de la RSE. La Secretaría del Consejo recae en la Dirección General de Economía Social, del Trabajo Autónomo y de la Responsabilidad Social de las Empresas.

En su primera etapa el Consejo Estatal creó los siguientes cinco grupos de trabajo que presentaron un informe de conclusiones:

a) El papel de la RSE ante la crisis económica: su contribución al nuevo modelo productivo, la competitividad y el desarrollo sostenible.

b) Transparencia, comunicación y estándares de los informes y memorias de sostenibilidad.

c) Consumo e Inversión Socialmente Responsable.

d) RSE y la Educación.

e) Gestión de la Diversidad, Cohesión Social y Cooperación al Desarrollo.

Tras finalizar su trabajo y presentar sus informes, en junio de 2011, el Consejo Estatal creó tres nuevos grupos de trabajo:

- Grupo sobre "Promoción de la RSE" para dar cumplimiento al mandato encomen- 
dado al CERSE en el artículo 39 de la Ley de Economía Sostenible.

- Grupo de Inversión Socialmente Responsable en Fondos de Pensiones (Disposición final trigésima primera de de la Ley de Economía Sostenible), con el objeto de dar recomendaciones al respecto.

- Grupo sobre Gestión y Funcionamiento del CERSE.

Terminada la legislatura en 2011, estos grupos aún no han presentado conclusiones claras sobre sus resultados.

Adicionalmente al desarrollo conceptual y asesor al Gobierno en materia de RSE, la Dirección General de Economía Social, del Trabajo Autónomo y de la Responsabilidad Social de las Empresas llevó a cabo Programas de apoyo (subvenciones) para la realización de estudios y jornadas realizadas por organizaciones sin ánimo de lucro que promocionan prácticas de RSE con los siguientes resultados:

- Concedidas en 2009: 1.281.166 euros (44 subvenciones)

- Concedidas en 2010: 1.487.838 euros ( 59 subvenciones)

- Concedidas en 2011: 1.135 .596 euros (61 subvenciones)

Pero ha sido la Ley de Economía Sostenible publicado en el BOE el pasado 5 de marzo de 2011, donde se han incorporado de forma más explícita medidas relacionadas con la RSE. En este sentido, destacan los artículos 35 sobre sostenibilidad en la gestión de empresas públicas, el artículo 39 sobre la promoción de la responsabilidad social de las empresas y, por último, la disposición final trigésimo primera. Aunque durante el texto de la Ley se pueden identificar otros artículos relacionados con la transparencia, la eficiencia energética, o el gobierno corporativo, entre otros, se resume a continuación el contenido de los tres artículos mencionados anteriormente por su especial trascendencia:

\section{Artículo 35. Sostenibilidad en la gestión de las empresas públicas}

Establece que las sociedades mercantiles estatales y las entidades públicas empresariales adscritas a la Administración General del Estado, en el plazo de un año desde la entrada en vigor de esta ley, adaptarán sus planes estratégicos para presentar anualmente informes de gobierno corporativo, así como memorias de sostenibilidad de acuerdo con estándares comúnmente aceptados, con especial atención a la igualdad efectiva entre mujeres y hombres y a la plena integración de las personas con discapacidad. También, recoge que las empresas públicas deben favorecer la implantación de prácticas de Responsabilidad Social de las Empresas en sus criterios de compra.

\section{Artículo 39. Promoción de la responsabilidad social de las empresas.}

Las Administraciones Públicas harán una política de promoción de la responsabilidad social dirigida a las organizaciones e instituciones públicas o privadas, empresas, especialmente a las pequeñas y medianas y a las empresas individuales.

En particular, el Gobierno pondrá a su disposición un conjunto de características e indicadores para su autoevaluación en materia de responsabilidad social, así como modelos o referencias de reporte, todo ello de acuerdo con los estándares internacionales en la materia.

Estas actuaciones atenderán a los objetivos de transparencia en la gestión, buen gobierno corporativo, compromiso con lo local y el medioambiente, respeto a los derechos humanos, mejora de las relaciones laborales, promoción de la integración de la mujer, de la igualdad efectiva 
entre mujeres y hombres, de la igualdad de oportunidades y accesibilidad universal de las personas con discapacidad y del consumo sostenible.

Para llevar a cabo esta labor se contará con las recomendaciones que, en este sentido, haga el Consejo Estatal de la Responsabilidad Social Empresarial.

La Ley establece que las sociedades anónimas de más de 1.000 asalariados, deberán hacer un informe anual de Responsabilidad Social Empresarial que será objeto de comunicación al Consejo Estatal de Responsabilidad Social Empresarial, lo que permitiría efectuar un adecuado seguimiento sobre el grado de implantación de las políticas de Responsabilidad Social Empresarial en las grandes empresas españolas. La ley matiza que el criterio será el de "cumplir o explicar", lo que quiere decir que las empresas podrán no presentarlo siempre que den una explicación.

Por último, con el objeto de que la Responsabilidad Social de las Empresas no sea una actuación que tan sólo afecta a la gran empresa, la Ley establece que cualquier empresa podrá solicitar voluntariamente ser reconocida como empresa socialmente responsable, de acuerdo con las condiciones que determine el Consejo Estatal de Responsabilidad Social Empresarial. En diciembre de 2011 estas condiciones todavía no se habían determinado.

\section{Disposición final trigésimo primera}

A través del texto se promueve el desarrollo reglamentario sobre difusión de información en política de inversión de fondos de pensiones. Se establece en la disposición que reglamentariamente se desarrollarán las condiciones para la difusión de la información sobre el uso de criterios sociales, medioambientales y de buen gobierno en la política de inversión de los fondos de pensiones.
En este sentido, la disposición final undécima de la Ley 27/2011, de 1 de agosto, sobre actualización, adecuación y modernización del sistema de Seguridad Social, recoge un avance en materia de fomentar la inversión socialmente responsable, al establecer una modificación de la Ley de regulación de los planes y fondos de pensiones de forma que "la comisión de control del fondo de pensiones, con la participación de la entidad gestora, elaborará por escrito una declaración comprensiva de los principios de su política de inversión. A dicha declaración se le dará suficiente publicidad. En esta declaración, en el caso de fondos de pensiones de empleo, se deberá mencionar si se tienen en consideración, en las decisiones de inversión, los riesgos extrafinancieros (éticos, sociales, medioambientales y de buen gobierno) que afectan a los diferentes activos que integran el fondo de pensiones. De la misma manera, la comisión de control del fondo de pensiones de empleo, o en su caso la entidad gestora, deberá dejar constancia en el informe de gestión anual del fondo de pensiones de empleo de la política ejercida en relación con los criterios de inversión socialmente responsable anteriormente mencionados, así como del procedimiento seguido para su implantación, gestión y seguimiento".

Cabe destacar que las iniciativas mencionadas parten desde la dirección general de RSE encuadrada dentro del Ministerio de Trabajo. Además de estas iniciativas han surgido en este periodo otras relevantes a la RSE desde el Ministerio de Industria (especialmente la Dirección General de la Pyme), el Ministerio de Sanidad y políticas sociales o el de medio ambiente, por citar algunos, además de en diferentes Comunidades autónomas y ayuntamientos pero, debido a las limitaciones de este trabajo se ha preferido 
no abordarlas al no poder hacerlo con la exhaustividad necesarias

\section{Punto de partida para converger la agenda española con la agenda europea de RSE}

Una vez analizadas las propuestas de la estrategia europea 2011-2014 y viendo el recorrido de las políticas públicas hasta el 2011, es el mo- mento de analizar cuál es el punto de partida para los próximos años y en qué ámbitos España se ha anticipado a algunas de las propuestas o necesita redoblar sus esfuerzos para consolidar un avance en las políticas de RSE en España. En la siguiente tabla se muestra la comparativa entre las demandas de la estrategia europea y la situación actual en España, estableciendo recomendaciones en algunos de los casos.

\section{Tabla 4 - Compromisos de la Comisión europea y recomendaciones para España}

\begin{tabular}{|c|c|c|}
\hline Líneas estratégicas europa & Compromisos Vomisión Europea & Situación España y recomendaciones \\
\hline \multirow{2}{*}{$\begin{array}{l}\text { Mejora de la visibilidad de la RSE } \\
\text { y difusión de buenas prácticas }\end{array}$} & $\begin{array}{l}\text { 1. Plataformas multilaterales sobre RSE en diver- } \\
\text { sos sectores industriales. }\end{array}$ & $\begin{array}{l}\text { No hay una iniciativa formal pero se puede } \\
\text { construir sobre las iniciativas ya existentes } \\
\text { (sector químico o logístico, por ejemplo) y } \\
\text { coordinarlas con las propuestas europeas. }\end{array}$ \\
\hline & $\begin{array}{l}\text { 2. Premio Europeo para asociaciones sobre RSE } \\
\text { entre empresas y partes interesadas. }\end{array}$ & $\begin{array}{l}\text { No existe un premio nacional avalado por el } \\
\text { Gobierno. Los premios del CSR Marketplace } \\
\text { de Forética son los de mayor prestigio coor- } \\
\text { dinados a nivel europeo con CSR Europe. }\end{array}$ \\
\hline \multirow{2}{*}{$\begin{array}{l}\text { Mejora y seguimiento de la con- } \\
\text { fianza en las empresas }\end{array}$} & $\begin{array}{l}\text { 3. Problema del marketing engañoso en relación } \\
\text { con las consecuencias medioambientales de } \\
\text { los productos; }\end{array}$ & $\begin{array}{l}\text { No existe una iniciativa que clarifique este } \\
\text { aspecto al consumidor. Lo más prudente } \\
\text { sería esperar una propuesta europea que } \\
\text { fomente la unidad de mercado. }\end{array}$ \\
\hline & $\begin{array}{l}\text { 4. Debate abierto con ciudadanos, empresas } \\
\text { y partes interesadas sobre el papel de las } \\
\text { empresas en el siglo XXI, y encuestas sobre la } \\
\text { confianza de los ciudadanos en las empresas } \\
\text { y la RSE. }\end{array}$ & $\begin{array}{l}\text { El Informe Forética y el estudio de CECU a } \\
\text { consumidores miden desde hace años al } \\
\text { clima de la RSE en España. Importante con- } \\
\text { struir sobre estas iniciativas. }\end{array}$ \\
\hline $\begin{array}{l}\text { Mejora de los procesos de autor- } \\
\text { regulación y corregulación }\end{array}$ & $\begin{array}{l}\text { 5. Elaboración de un código de buenas prác- } \\
\text { ticas sobre autorregulación y corregulación } \\
\text { que debe mejorar la eficacia del proceso de } \\
\text { RSE. }\end{array}$ & $\begin{array}{l}\text { Incluido en propuesta de la LES, art.39. En } \\
\text { España más de } 100 \text { empresas siguen el } \\
\text { código marcado por la SGE } 21 .\end{array}$ \\
\hline \multirow[b]{2}{*}{$\begin{array}{l}\text { Mejora de la recompensa que } \\
\text { supone la RSE en el mercado }\end{array}$} & $\begin{array}{l}\text { 6. Integración de las consideraciones sociales y } \\
\text { medioambientales en la contratación pública. }\end{array}$ & $\begin{array}{l}\text { Incorporado en la ley de contratos del Es- } \\
\text { tado. Importante coordinar con las propu- } \\
\text { estas que se establezcan en Europa. }\end{array}$ \\
\hline & $\begin{array}{l}\text { 7. Los fondos de inversión e instituciones finan- } \\
\text { cieras informen a sus clientes sobre cualquier } \\
\text { criterio de inversión ético o responsable que } \\
\text { apliquen o cualquier norma o código al que } \\
\text { se adhieran. }\end{array}$ & Incluido en la LES y la ley 27/2011 \\
\hline
\end{tabular}




\begin{tabular}{|c|c|c|}
\hline $\begin{array}{l}\text { Mayor integración de la RSE en } \\
\text { la educación, la formación y la } \\
\text { investigación }\end{array}$ & $\begin{array}{l}\text { 8. Apoyo financiero a proyectos de educación } \\
\text { y formación sobre RSE y sensibilizar académi- } \\
\text { cos y empresas sobre importancia } \\
\text { de la cooperación. }\end{array}$ & $\begin{array}{l}\text { Existen gran número de cátedras, cursos } \\
\text { y másters de RSE, sigue siendo necesario } \\
\text { potenciar su coordinación con empresas }\end{array}$ \\
\hline $\begin{array}{l}\text { Insistencia en la importancia de } \\
\text { las políticas nacionales y subna- } \\
\text { cionales sobre RSE }\end{array}$ & $\begin{array}{l}\text { 9. crear con los Estados miembros, un } \\
\text { mecanismo de revisión por pares de las } \\
\text { políticas nacionales en materia de RSE. }\end{array}$ & $\begin{array}{l}\text { Necesidad de un plan de acción de RSE } \\
\text { con objetivos e indicadores de segui- } \\
\text { miento. }\end{array}$ \\
\hline $\begin{array}{l}\text { Mejora de la armonización de } \\
\text { los enfoques europeo y mundial } \\
\text { sobre RSE }\end{array}$ & $\begin{array}{l}\text { 10. seguimiento del compromiso de empresas } \\
\text { europeas integrar RSE en sus operaciones. } \\
\text { 11. elaborar orientaciones sobre derechos } \\
\text { humanos para sectores industriales sobre la } \\
\text { base de los Principios Rectores de la ONU; } \\
\text { 12. informe de la UE de aplicación de los Prin- } \\
\text { cipios Rectores de la ONU y emitir informe } \\
\text { periódico. } \\
\text { 13. promover el comportamiento responsable } \\
\text { de las empresas en terceros países. }\end{array}$ & $\begin{array}{l}\text { Seguimiento previsto por el CERSE } \\
\text { Seguir las pautas que se establezcan en } \\
\text { Europa para los compromisos } 11,12 \text { y } 13 \text {. }\end{array}$ \\
\hline $\begin{array}{l}\text { Mejora de la divulgación de } \\
\text { información de carácter social y } \\
\text { medioambiental } \\
\text { por parte de las empresas }\end{array}$ & $\begin{array}{l}13+1 \text {. Nueva propuesta legislativa sobre } \\
\text { reporting RSE }\end{array}$ & Incorporada en la LES \\
\hline
\end{tabular}

Respecto a las invitaciones que hace a los diversos grupos de interés, lo más prioritario sería responder a la demanda a los Estados miembros a elaborar, o actualizar sus propios planes de acciones prioritarias para promover la RSE en apoyo de la Estrategia Europa 2020, con respecto a principios y directrices de RSE reconocidos internacionalmente y en cooperación con las empresas y otras partes interesadas. La comisión propone que esta revisión se haga antes de mediados de 2012 y sería muy importante que España mostrara liderazgo en este ámbito presentando una plan de acción de RSE a la altura de los por ejemplo ya mencionados de los gobiernos alemán y danés.

\section{Conclusiones}

La publicación de cualquier estrategia siempre lleva aparejada la pregunta de cuántos de los compromisos que se establecen podrán final- mente llevarse a cabo. Sólo el compromiso de la comisión europea y de los estados miembros sumidos en estos momentos en un debate sobre cómo articular la Unión Europea podrá definir si en 2014 se cumple con lo previsto. En cualquier caso, la estrategia europea de RSE confirma el interesante momento de esta disciplina que, debido a su complejidad, requiere de compromisos transnacionales y al mayor nivel. Además requiere de un liderazgo sólido tanto a nivel político como a nivel empresarial.

Como ante cualquier estrategia, podemos establecer un listado de aspectos que demuestran su fortaleza así como los elementos que desde el ámbito de la RSE nos hubiera gustado ver más reforzados. Entre los primeros, los aspectos positivos, se podrían destacar los siguientes:

- Una nueva definición de RSE más sencilla pero que en su parte extendida refleja un 
concepto de creación de valor y fomento de la innovación, mucho más rico que el de la simple gestión de riesgos.

- Una aceptación de la necesidad de flexibilidad de las empresas para innovar (también en aspectos sociales y de buen gobierno, por ejemplo).

- La clarificación de algunos aspectos como la inclusión del voluntariado corporativo como una de las prácticas de RSE.

- La intención de la Comisión europea de colaborar con la iniciativa empresarial de CSR Europe denominada "Enterprise 2020"

- Un énfasis fuerte en la dimensión internacional de la RSE y la coordinación con herramientas globales.

- La ambición por coordinar planes nacionales de RSE para evitar divergencias.

- Un gran número de iniciativas que proponen la participación y el diálogo abierto con todos los grupos de interés.

Entre las debilidades encontramos en este momento:

- La debilidad del propio debate europeo con la esperanza de que se establezca un marco claro de cara al 2012

- La propia Comisión Europea debería haberse comprometido a publicar su propio informe de transparencia en materia de RSE o clarificar su política de compras en esta materia.

- No queda de momento clara la forma en que los líderes empresariales pueden hacer efectivo su compromiso y de qué forma se rinden cuentas.

De cara a España deberíamos aprovechar los compromisos establecidos en la Ley de Econo- mía sostenible y perfeccionar el funcionamiento y la composición del CERSE. A partir de ahí y de la elaboración de la estrategia española de RSE que tenga en consideración las iniciativas y los actores que han liderado este campo en los últimos años y tome como partida algunas de las iniciativas que ya se han ido consolidando en los terrenos de la investigación, la formación o las prácticas de empresas. Por supuesto, y por último, establecer los mecanismos de seguimiento para verificar el cumplimiento de las propuestas y analizar los indicadores que puedan determinar avances o retrocesos en la aplicación de estas prácticas tanto en empresas como en cualquier tipo de organizaciones.

La Comisión Europea destaca por su parte, en las conclusiones de su estrategia, que "trabajará con los Estados miembros, las empresas y otras partes interesadas para hacer un seguimiento periódico de los avances y preparar conjuntamente una reunión de revisión, que se celebrará a más tardar a mediados de 2014".

Además, la Comisión pide a los líderes empresariales europeos que suscriban, antes de mediados de 2012, "un compromiso abierto de promover, en estrecha cooperación con los poderes públicos y otras partes interesadas, la adopción de una gestión empresarial responsable por parte de un mayor número de empresas de la UE, con objetivos claros para 2015 y 2020".

A partir de aquí será tarea de la Comisión Europea, los gobiernos nacionales, las empresas y las organizaciones que trabajan por promocionar la RSE que esta ambiciosa estrategia quede en papel mojado o consiga ser un revulsivo para realizar un pequeño nuevo avance hacia una sociedad más responsable y sostenible. 


\section{Bibliografía}

Comisión Europea (2008) Informe de 2008 sobre la Competitividad en Europa [COM (2008) 774]

Comisión Europea (2010) Una política industrial integrada para la era de la globalización, COM (2010) 614.

Comisión Europea (2011) Acta del Mercado Único Doce prioridades para estimular el crecimiento y reforzar la confianza «Juntos por un nuevo crecimiento» COM (2011) 206 Comisión Europea (2011) Estrategia renovada de la UE para 2011-2014 sobre la responsabilidad social de las empresas COM (2011) 681.

Comisión Europea,(2011) «Responsabilidad Social de las Empresas: Políticas Públicas Nacionales en la UE».
Comisión europea (2011) «Comunicación sobre políticas de la UE y voluntariado: Reconocimiento y fomento de actividades voluntarias transfronterizas en la UE», COM(2011) 568.

Forética (2008) SGE 21 Sistema de Gestión Ética y Socialmente Responsable

Forética (2011) Informe Forética 2011. Situación de la RSE en España.

Ley 2/2011, de 4 de marzo de Economía Sostenible Ley 27/2011, de 1 de agosto, sobre actualización, adecuación y modernización del sistema de Seguridad Social Ministerio de Trabajo e Inmigración (2011) Balance en materia de responsabilidad social de las empresas (RSE) 20082011. www.mtin.es 
